\title{
RhoA signaling in phorbol ester-induced apoptosis
}

\author{
Zee-Fen Chang* \& Hsiao-Hui Lee \\ Institute of Biochemistry and Molecular Biology, College of Medicine, National Taiwan University, No. 1, \\ Section 1, Jen-Ai Road, Taipei, Taiwan, ROC
}

(c) 2006 National Science Council, Taipei

Key words: apoptosis, phorbol ester, Rho A

\begin{abstract}
Summary
Exposure of cells to phorbol ester activates protein kinase C (PKC) to induce apoptosis or differentiation, depending on the cellular context. In erythroblastic cell lines, TF-1 and D2, upregulation of the RhoA signaling promotes phorbol ester-induced apoptosis through activating Rho-associated kinase (ROCK)/ phosphorylation of myosin light chain (MLC), thus generating membrane contraction force. As a result, cell adhesion is inhibited and death receptor-mediated death pathway is activated in these cells with a concurrent changes in nucleocytoplasmic signaling for protein trafficking. A microtubule-regulated GEF$\mathrm{H} 1$, which is a specific RhoA activator, was identified to contribute to RhoA activation in these cells. Thus, a cytoskeleton-regulated RhoA signaling cooperates with PKC activation constitutes a cellular context to determine the cell fate in response to phorbol ester stimulation.
\end{abstract}

\section{Introduction}

Tissue homeostasis in multicellular organism is achieved by coordination and balance between cell proliferation, differentiation and apoptosis. The molecular mechanisms for integrating signals from the environment to achieve this orchestral coordination are complicated and dynamic. To dissect the interaction between signal pathways from environment cue and the existing cellular context, it is necessary to first define the molecular context responsible for cell fate decision in response to one particular type of stimulus. When exposed to phorbol-12-myristate-13-acetate (PMA), an activator of novel and classical PKCs, hematopoietic cells can be induced to differentiation or apoptosis depending on the cell types [1-6]. Presumably, signal from PKC activation emerges different signal pathways in the cells, resulting in differential cellular responses [7]. We previously used erythro-

*To whom correspondence should be addressed. Fax: 886-22395-8904; E-mail: zfchang@ha.mc.ntu.edu.tw blastoma cells as a model system to study the molecular context responsible for PMA-induced apoptosis, which led us to find the involvement of RhoA signal pathway. In this review article, we will discuss how the molecular context regulated by RhoA signaling leads to PMA-induced apoptosis.

The growth of myeloid progenitor TF-1 cells is dependent on granulocyte/macrophage colonystimulating factor (GM-CSF) and interleukin 3 [8]. Upon treatment with PMA, approximately $15 \%$ of the cells differentiate into macrophage-like cells and attach to the culture dishes, whereas the other $85 \%$ of the population remain in suspension and become apoptotic [9]. A few TF-1 variants, which grow autonomously in medium without supplementation of GM-CSF or interleukin 3, have previously been selected and characterized [9]. D2 is one of the variant cell lines that show $50 \%$ of the cells differentiating and the other $50 \%$ apoptotic after PMA stimulation [9]. Removal of serum resulted in all D2 or TF-1 cells adherent to the culture dishes and prevented cells from PMA-induced apoptosis, while addition of 
lysophosphatidate (LPA) to serum-free medium increased PMA-induced apoptosis [10]. Prevention of cell adhesion by plating cells onto hydrogelcoated dishes caused all cells apoptosis upon PMA treatment [11], indicating that the LPA-mediated signal pathway changes cell adhesion capacity, thus promoting PMA-induced apoptosis. Expression of $\mathrm{C} 3$, a specific inhibitor of RhoA, was able to abrogate LPA-mediated promoted apoptosis, and expression of dominant active form of $\mathrm{G} \alpha 12$ / 13 increased PMA-induced apoptosis in serumfree medium. These evidence clearly show that LPA/GPCR/G $\alpha 12 / 13 /$ RhoA pathway contributes to a cellular context that affects the cellular response to PMA induction [10]. On this basis, a series of downstream events of RhoA pathway were found to be involved in PMA-induced apoptosis in this model system.

\section{RhoA-signaling and morphological change}

The Rho GTPases are a family of proteins involved in multiple cellular processes, including cytoskeletal organization, gene expression and transformation $[12,13]$. Among them RhoA is known to coordinate with other signal pathway to control dynamic rearrangements of the actin cytoskeleton, which are central to the morphological changes observed in apoptosis [14-16]. It has been shown that activation of RhoA is responsible for the contraction observed in the apoptotic cells induced by serum starvation, and ectopic expression of dominant active form of RhoA is sufficient to induce apoptosis [17-19]. Among the diverse downstream effectors of RhoA, two forms of serine/threonine kinases (ROCK I and ROCK II) have been shown to mediate RhoA signaling in membrane contraction force during apoptosis $[20,21]$. The kinase activity of ROCK is autoinhibited via the interaction between its $\mathrm{C}$-terminal inhibitory domain and $\mathrm{N}$-terminal kinase region. Upon binding to the GTP-bound form of RhoA at its C-terminal inhibitory region, the kinase activity of ROCK is enhanced due to the relief of autoinhibition [20,22]. ROCK regulates the phosphorylation of myosin light chain (MLC) by directly phosphorylating MLC at Thr18 and Ser19, and by the inactivation of myosin phosphatase [23, 24]. Phosphorylation of MLC activates myosin ATPase activity, which couples with actin-myosin filaments to the plasma membrane, thus increasing the actomyosin force generation and cell contractility. It has been shown that in apoptotic cells ROCK I is cleaved by caspase-3, which removes its C-terminal inhibitory region [25, 26], thus activating its kinase function and increasing MLC phosphorylation, resulting in membrane contraction. This mechanism contributes to formation of membrane blebbing in apoptotic cells. Distinct from these late-stage-apoptotic cells with caspase-3 activation, in PMA-induced pro-apoptotic cells ROCK-mediated MLC phosphorylation indeed occurs earlier than caspase-3 activation [11]. In fact, inhibition of ROCK by its specific inhibitor, Y27632 [27], prevented PMAinduced activation of caspase-3 in suspension cells, thus abrogating apoptosis. Therefore, ROCK activation in PMA-induced pro-apoptotic cells acts as an upstream event required for membrane contraction and the subsequent caspase- 3 activation during PMA stimulation [11].

We have compared the distribution of F-actin in PMA-induced pro-apoptotic and differentiating cells. As a contrast to untreated D2 cells where cortical F-actin was detected, one pronounced F-actin aggregate was specifically observed in proapoptotic population of cells [unpublished data], accompanied by a significant increase of MLC phosphorylation. Perhaps, too much contraction in pro-apoptotic cells caused a severe collapse of F-actin network, disrupting the interconnection between plasma membrane and F-actin-mediated structure. This structural change may therefore affect membrane microdomain, disabling the function of membrane receptors required for adhesion and death signaling.

\section{Activation of RhoA signaling in PMA-induced pro-apoptotic cells}

Rho A cycles between a GDP-bound inactive state and a GTP-bound active state. Activation is accomplished by guanine nucleotide exchange factors that (GEF) favor the release of bound GDP and subsequent GTP loading. Currently, LARG [28, 29], PDZ-RhoGEF [30], p115RhoGEF [31], AKAP-Lbc [32], and GEF-H1 are the known RhoA GEF proteins controlling RhoA activation. By GST-RhoA pull-down analysis, we identified GEF-H1 abundantly present in the cytosolic soluble fraction of D2 cells [33]. GEF-H1 is a 
microtubule-associated GEF, whose function in RhoA depends on its subcellular localization [3436]. In HeLa cells, GEF-H1 associates with microtubules, where GEF-H1 loses its RhoA activation function. During microtubule depolymerization in mitosis or nocodazole-treated cells, GEF-H1 is released to the cytoplasm and activates RhoA [34], which plays a role in generating the contractile force during mitosis [37]. Consistent with its localization-dependent function, in PMAinduced pro-apoptotic cells, GEF-H1 stayed in cytoplasm fraction, whereas in the attached cells GEF-H1 is associated with microtubules [33]. Depletion of GEF-H1 expression in D2 cells under serum-free incubation condition caused a significant reduction of RhoA activity. As a result, these cells did not undergo PMA-induced contraction and the subsequent cell death was prevented. Accordingly, our current hypothesis is that cytosolic GEF-H1 in suspension D2 cells constitutes a cellular context for sustained activation of RhoA, which is required for ROCK-dependent contraction in response to PMA stimulation. In PMA-induced differentiating cells, GEF-H1 is sequestered by the more organized microtubules and is unable to activate RhoA/ROCK signaling, thus allowing cells to survive with adhesion and spreading. At present, the mechanism underlying the differential subcellular localization of GEF-H1 in PMA-induced pro-apoptotic and differentiating cells remains to be investigated. Since microtubule organization is very different in PMA-induced proapoptotic cells and adherent cells, it is likely that there is positive feedback in RhoA activation by microtubule disassembly during apoptotic induction.

\section{Nucleocytoplasmic trafficking}

The nucleocytoplasmic shuttling of signaling factors confers the spatial regulation of protein activity and may also acts as an integral part of the apoptotic program by controlling apoptotic regulators migrated in and out of the nucleus. Several proteins implicated in apoptotic execution including FADD [38], TRADD [39], DEDD [40], and Apaf-1 [41, 42], have been shown to change their nucleoplasmic trafficking in response to apoptotic stimulation. Relevant to this, our laboratory has previously shown that activated extra- cellular signal-regulated kinase (ERK) is unable to be translocated into nuclei in PMA-induced proapoptotic TF-1 and D2 cells, and this disabled translocation of activated ERK is responsible for lack of cyclin kinase inhibitor p21 induction in response to PMA in this population of cells [43]. Inhibition of ROCK by its specific inhibitor Y27632 could rescue these cells from PMA-induced apoptosis and restore nuclear translocation of activated ERK, indicating that ROCKmediated signal also affects protein trafficking during apoptosis [43]. Here, it should be mentioned that the nuclear translocation of other protein with NLS-signal is not affected by PMAinduced contraction in our cell system. Although it has shown that adhesion is required for ERK nuclear translocation, we found that the relief of contraction force by inhibiting actin polymerization can restore nuclear translocation of phosphorylated ERK and prevent apoptosis in the suspension D2 and TF-1 cells, indicating that adhesion does not play a necessary role in ERK translocation. Rather, it is surely that contraction force specifically exerts an inhibitory effect on its transport machinery.

In addition to the effect on phosphorylated ERK nuclear translocation, ROCK activation in PMA-induced pro-apoptotic cells causes cytosolic translocation of nuclear protein hnRNP $\mathrm{C} 1 / \mathrm{C} 2$ independent of caspase activation [44]. This translocation phenomenon can also be observed in TNF $\alpha$-induced apoptotic NIH3T3 cells, where ROCK I activation is dependent on caspase-3mediated cleavage. The hnRNP $\mathrm{C} 1 / \mathrm{C} 2$ proteins are members of a large family of RNA-binding proteins that influence pre-mRNA processing, mRNA metabolism, and mRNA transport [4550]. Because other major hnRNP proteins, hnRNP $\mathrm{A} 2 / \mathrm{B} 1$, nuclear matrix proteins, lamin $\mathrm{A} / \mathrm{C}$, and general transcription factor $\mathrm{Sp} 1$ still stay in the nuclear compartment of PMA-induced pro-apoptotic cells, efflux of hnRNP $\mathrm{Cl} / \mathrm{C} 2$ is a rather specific event controlled by ROCK activation [44]. Unlike other hnRNP members which shuttles between nucleoplasmic and cytoplasm compartments, hnRNP $\mathrm{Cl} / \mathrm{C} 2$ are nuclear restricted proteins due to the presence of their nuclear retention sequence (NRS) [51]. Various C-terminus deleted forms of hnRNP $\mathrm{Cl}$, which contain NRS, are retained in nuclei irrespective to expression of dominant active form of ROCK(CAT), indicating 
that the efflux of hnRNP $\mathrm{C} 1 / \mathrm{C} 2$ proteins is not due to the impairment of NRS-mediated nuclear retention mechanism. Since overexpression of dominant active form of ROCK is sufficient to induce a nuclear reporter YFP fused with Cterminal 40 amino acids of hnRNP $\mathrm{C} 1$, this sequence is considered as a novel ROCK-responsive nuclear export sequence (NES) [44].

Since depletion of hnRNP C1/C2 does not cause cell death [52], the physiological meaning of ROCK-responsive translocation of hnRNP C1/C2 in apoptosis awaits further investigation. It will be interesting to know whether this efflux process may mediate the exclusion of other protein important for nuclear structure and function, thus making a significant alteration in nuclear morphology and function in apoptosis. In addition to the function of hnRNPC1/C2 in nuclei, the hnRNPC1/C2 proteins have also been found to bind to mRNA to mediate cap-independent translation by the mechanism involving internal ribosome entry site (IRES) [53-55]. Member of the inhibitor of apoptosis (IAP) (XIAP) is known to be translated using an IRES, allowing for the continued translation of XIAP under condition where cap-dependent translation is inhibited in apoptosis. It has been shown that the binding of hnRNP $\mathrm{C} 1 / \mathrm{C} 2$ to IRES increases XIAP IRES function. Accordingly, it is, therefore, possible that ROCK-mediated shuttling hnRNP C1/C2 to cytoplasm may also provide a means to regulation XIAP protein expression under pro-apoptotic stress.

\section{The involvement of death pathway}

In PMA-induced apoptotic D2 cells, activation of caspase- 3 is seen after $6 \mathrm{~h}$ of PMA treatment. Coincubation with general caspase inhibitor does not affect PMA-induced contraction, but abrogates cell death, indicating that contraction acts upstream of caspase activation [11]. It is well established that both intrinsic and extrinsic pathways can activate caspase-3 in response to various apoptotic stimuli [56]. A pro-apoptotic signal generated from death receptor (extrinsic) and mitochondria (intrinsic) can activate an initiator or upstream caspase, which usually possesses a long $\mathrm{NH}_{2}$-terminal prodomain such as caspases-8, -10 , and -9 , respectively [57-59]. In turn, these initiators can activate the effector caspases, such as caspases-3, -6, which result in apoptotic execution. One of the best-defined apoptotic pathways is mediated by the death receptors such as CD95 or tumor necrosis factor receptors (TNFRs). Upon ligand binding, the intracellular death domain of death receptor recruits Fas-associated death domain protein (FADD) through protein-protein interaction. FADD links the receptor to the apoptotic caspase, pro-caspase- 8 or -10 , through homotypic interactions of death effector domains (DED), to form a death-inducing signaling complex (DISC); this in turn leads to oligomerization and activation of these two zymogens by self cleavage and the subsequent apoptotic cascade [60-63].

Unlike the finding showing that ROCK is activated by caspase-3-mediated cleavage in apoptotic cells, in PMA-induced apoptotic D2 cells, ROCK activation works upstream of caspase-3 activation. In these apoptotic cells, we found that both caspase- 8 and -10 are the apical caspases and their activation is a result of membrane contraction dependent on ROCK, by which effector caspase-3 is activated to trigger this apoptotic pathway. Moreover, complex containing endogenous FADD with procaspase-10 is preferentially formed in PMA-induced pro-apoptotic cells, but not the survived cells [11]. Since inhibition of ROCK prevents caspase activation, we conclude that activation of RhoA/ROCK/MLC phosphorylation pathway in cooperation with PMA signaling in cells provides a cellular context that generates an initial membrane contraction, leading to activation of caspase- 8 and -10 through a mechanism involving membrane receptor-mediated signaling. Relevant to this observation, it has been reported that MLCK-mediated MLC phosphorylation increases translocation of tumor necrosis factor receptor (TNFR) to the plasma membrane independent of TNF signal, which in turn activates caspase- 8 to initiate the apoptotic pathway [64]. Other study has also shown that treatment of cells with cytoskeleton disturbing reagent cytochalasin $\mathrm{B}$ increases clustering of the CD95 receptor to activate caspase8 and enhances UV-induced apoptosis [65]. Therefore, it seems to be general that actomyosinmediated contraction force can act as a factor promoting activation of death receptor pathway.

Distinct to our findings, other study has shown that phorbol ester induces apoptosis in U937 cells, 
in part, through a pathway, which requires endogenous production of TNF $\alpha$ depending on activation of MEK/ERK during stimulation [66]. In the case of PMA-induced apoptosis of androgendependent prostate cancer cells, it has been shown to PKC $\delta$ participates in activation of the extrinsic death receptor pathway via TNF $\alpha$ and TRAIL receptors by stimulating the releases of their ligands [67]. However, PMA-induced apoptosis in TF-1 cells did not require newly synthesized protein, neither did pre-incubated cells with recombinant TNF receptor R1 protein to sequester TNF ligand prevents PMA-induced apoptosis, thus excluding the possibility that TNF ligand binding is involved in this apoptotic process [11]. It should be mentioned that expression of dominant negative form of FADD decreased but not completely abolished PMA-induced apoptosis in D2 and TF-1 cells, implying that the death receptormediated pathway probably only plays a partial role in PMA-induced apoptosis. It has been demonstrated that unligated integrins recruit caspase- 8 to the membrane and form the DISC without FADD, suggesting the presence of a death receptor-independent caspase- 8 activation mechanism [68]. Therefore, it will be interesting to further look at the involvement of other receptor pathway in this apoptotic process.

\section{Action of protein kinase $\mathrm{C}$ and $\mathrm{RhoA}$ signaling in apoptosis}

PKC is a family of phospholipids-dependent serine/threonine kinases comprising 10 isoenzymes [69]. These PKC isoenzymes are subdivided into three classes (i) the 'conventional' PKCs PKC $\alpha$ PKC $\beta$ PKC $\gamma$ which can be activated by phosphatidylserine, diacyl glycerol (DAG), or phorbol esters through binding to the $\mathrm{C}-1$ domain and $\mathrm{Ca}^{2+}$ through binding to $\mathrm{C}-2$ region; (ii) the 'novel' PKCs PKC $\delta, \operatorname{PKC} \varepsilon, \operatorname{PKC} \theta$, PKC $\eta$ lack the $\mathrm{C}-2$ region and thus are calcium-independent but still DAG-, phosphatidylserine-, and phorbol ester-responsive; and (iii) the 'atypical' PKCs PKC $\lambda / \imath$ and PKC $\xi$ also lack the C-2 region and a functional DAG-binding site; hence they are only responsive to phosphatidylserine but not to DAG or phorbol ester. Since PKC inhibition blocked PMA-induced apoptosis in D2 cells [unpublished data], one important question is which PKC isoform works together with RhoA signaling to trigger apoptosis. Several studies showed the linkage between PKC and RhoA signaling [7073]. PKC-induced activation of Src kinase activity has been shown to phosphorylate p190RhoGAP, which subsequently down-regulates RhoA activity [74]. On the other hand, it has been shown that RhoA is activated by PKC-mediated phosphorylation. In our system, we found expression of dominant active form of ROCK is insufficient to induce apoptosis. Therefore, it is likely that other signal pathway via PKC activation is also required for PMA-induced apoptosis.

PKCs reside in the cytosol in an inactive conformation and translocate to the membrane upon activation where they modify various cellular functions through phosphorylation of target substrates [75]. In both PMA-induced differentiating and pro-apoptotic fractions of D2 cells, there was no difference in membrane translocation of various PKC isoforms, $\alpha, \beta, \gamma, \delta, \varepsilon$ and $\theta$ [10]. although activation of PKC $\delta$ has been shown to induce apoptosis in leukemic cells, we did not find that expression of dominant negative form of PKC $\delta$ has an effect on reducing PMA-induced contraction. Nevertheless, it is still possible that the differences in cytoskeletal reorganization of suspension and adhesion cells make the difference in downstream events of PKC activation, which emerges RhoA/ROCK signaling in membrane contraction for death receptor-mediated caspase activation. From this point, it should be mentioned again, activated ERK via PKC pathway stayed in the cytosol of suspension pro-apoptotic cells. Inhibition of ERK activation by MEK inhibitor U0126 prevented PMA-induced apoptosis, indicating PKC-ERK pathway also participates in death induction. So, how does activated ERK in cytosol get involved in contraction for apoptotic induction? It appears that death-associated protein kinase (DAPK) in cytosol interacts with ERK [76]. DAPK is a DD-containing calmodulin (CaM)-regulated serine/threonine kinase, which functions as a positive mediator of apoptosis induced by a variety of stimuli, such as interferon- $\gamma$, Fas, TNF- $\alpha$, TGF- $\beta$, ceramide and oncogenes c-myc and E2F [77-83]. Phosphorylation of DAPK by cytosolic sequestered ERK increased its in vitro and in vivo kinase activity. Knock down of DAPK by RNA interference increased cell survival after PMA stimulation [76], 
suggesting DAPK plays a key role in the downstream effector of PKC/ERK pathway in PMAinduced apoptosis. Although MLC is a substrate of DAPK in vitro, we did not find extent of MLC phosphorylation to be affected by inhibition of ERK activation, excluding the possibility that the ERK-DAPK pathway in PMA-induced pro-apoptotic cells can confer the increment of MLC phosphorylation. At present, it remains a challenge to dissect the signaling events regulated by individual PKCs and DAPK in collaboration with ROCK activation for generating the apoptotic contractility in PMA-induced pro-apoptotic cells.

\section{Conclusion remark}

In summary, studies on PMA-induced pro-apoptotic in TF-1 and D2 cells have introduced a novel paradigm that cytoskeletal organization regulated by RhoA signaling plays a pivotal role in affecting the flow of PKC signaling pathways, thus eliciting effect on both nucleoplasmic trafficking and death receptor pathways. Understanding the interaction between cytoskeletal regulation and PKC activation pathway may have significant therapeutic relevance, since PKC activators (including phorbol esters) are in clinical trials for various types of cancers [84-86].

\section{References}

1. Day M.L., Zhao X., Wu S., Swanson P.E. and Humphrey P.A., Phorbol ester-induced apoptosis is accompanied by NGFI-A and c-fos activation in androgen-sensitive prostate cancer cells. Cell Growth Differ. 5: 735-741, 1994.

2. Garzotto M., White-Jones M., Jiang Y., Ehleiter D., Liao W.C., Haimovitz-Friedman A., Fuks Z. and Kolesnick R., 12-O-Tetradecanoylphorbol-13-acetate-induced apoptosis in LNCaP cells is mediated through ceramide synthase. Cancer Res. 58: 2260-2264, 1998.

3. Lotem J., Cragoe E.J. Jr. and Sachs L., Rescue from programmed cell death in leukemic and normal myeloid cells. Blood 78: 953-960, 1991.

4. Collins S.J., The HL-60 promyelocytic leukemia cell line: proliferation, differentiation, and cellular oncogene expression. Blood 70: 1233-1244, 1987.

5. Gunji H., Hass R. and Kufe D., Internucleosomal DNA fragmentation during phorbol ester-induced monocytic differentiation and $\mathrm{G} 0 / \mathrm{G} 1$ arrest. J. Clin. Invest. 89: 954 960, 1992.

6. Kizaki H., Tadakuma T., Odaka C., Muramatsu J. and Ishimura Y., Activation of a suicide process of thymocytes through DNA fragmentation by calcium ionophores and phorbol esters. J. Immunol. 143: 1790-1794, 1989.
7. Nishizuka Y., The molecular heterogeneity of protein kinase $\mathrm{C}$ and its implications for cellular regulation. Nature 334: 661-665, 1988.

8. Kitamura T., Tange T., Terasawa T., Chiba S., Kuwaki T., Miyagawa K., Piao Y.F., Miyazono K., Urabe A. and Takaku F., Establishment and characterization of a unique human cell line that proliferates dependently on GM-CSF, IL-3, or erythropoietin. J. Cell Physiol. 140: 323-334, 1989.

9. Chao J.R., Chen C.S., Wang T.F., Tseng L.H., Tsai J.J., Kuo M.L., Yen J.J. and Yang Yen H.F., Characterization of factor-independent variants derived from TF-1 hematopoietic progenitor cells: the role of the Raf/MAP kinase pathway in the anti-apoptotic effect of GM-CSF. Oncogene 14: 721-728, 1997.

10. Lai J.M., Lu C.Y., Yang-Yen H.F. and Chang Z.F., Lysophosphatidic acid promotes phorbol-ester-induced apoptosis in TF-1 cells by interfering with adhesion. Biochem. J. 359: 227-233, 2001.

11. Lai J.M., Hsieh C.L. and Chang Z.F., Caspase activation during phorbol ester-induced apoptosis requires ROCKdependent myosin-mediated contraction. J. Cell Sci. 116: 3491-3501, 2003.

12. Etienne-Manneville S. and Hall A., Rho GTPases in cell biology. Nature 420: 629-635, 2002.

13. Hall A., Rho GTPases and the actin cytoskeleton. Science 279: 509-514, 1998.

14. Aznar S. and Lacal J.C., Rho signals to cell growth and apoptosis. Cancer Lett. 165: 1-10, 2001.

15. Coleman M.L. and Olson M.F., Rho GTPase signalling pathways in the morphological changes associated with apoptosis. Cell Death Differ. 9: 493-504, 2002.

16. Kaibuchi K., Kuroda S. and Amano M., Regulation of the cytoskeleton and cell adhesion by the Rho family GTPases in mammalian cells. Annu. Rev. Biochem. 68: 459-486, 1999.

17. Dubreuil C.I., Winton M.J. and McKerracher L., Rho activation patterns after spinal cord injury and the role of activated Rho in apoptosis in the central nervous system. J. Cell Biol. 162: 233-243, 2003.

18. Esteve P., Embade N., Perona R., Jimenez B., del Peso L., Leon J., Arends M., Miki T. and Lacal J.C., Rho-regulated signals induce apoptosis in vitro and in vivo by a p53independent, but $\mathrm{Bcl} 2$ dependent pathway. Oncogene 17: 1855-1869, 1998.

19. Jimenez B., Arends M., Esteve P., Perona R., Sanchez R., Ramon y Cajal S., Wyllie A. and Lacal J.C., Induction of apoptosis in NIH3T3 cells after serum deprivation by overexpression of rho-p21, a GTPase protein of the ras superfamily. Oncogene 10: 811-816, 1995.

20. Amano M., Fukata Y. and Kaibuchi K., Regulation and functions of Rho-associated kinase. Exp. Cell Res. 261: 44 $51,2000$.

21. Matsui T., Amano M., Yamamoto T., Chihara K., Nakafuku M., Ito M., Nakano T., Okawa K., Iwamatsu A. and Kaibuchi K., Rho-associated kinase, a novel serine/ threonine kinase, as a putative target for small GTP binding protein Rho. EMBO J. 15: 2208-2216, 1996.

22. Riento K. and Ridley A.J., Rocks: multifunctional kinases in cell behaviour. Nat. Rev. Mol. Cell Biol. 4: 446-456, 2003.

23. Amano M., M. Ito, Kimura K., Fukata Y., Chihara K., Nakano T., Matsuura Y. and Kaibuchi K., Phosphorylation and activation of myosin by Rho-associated kinase (Rho-kinase). J. Biol. Chem. 271: 20246-20249, 1996.

24. Kimura K., Ito M., Amano M., Chihara K., Fukata Y., Nakafuku M., Yamamori B., Feng J., Nakano T., Okawa 
K., Iwamatsu A. and Kaibuchi K., Regulation of myosin phosphatase by Rho and Rho-associated kinase (Rhokinase). Science 273: 245-248, 1996.

25. Coleman M.L., Sahai E.A., Yeo M., Bosch M., Dewar A. and Olson M.F., Membrane blebbing during apoptosis results from caspase-mediated activation of ROCK I. Nat. Cell Biol. 3: 339-345, 2001.

26. Sebbagh M., Renvoize C., Hamelin J., Riche N., Bertoglio J. and Breard J., Caspase-3-mediated cleavage of ROCK I induces MLC phosphorylation and apoptotic membrane blebbing. Nat. Cell Biol. 3: 346-352, 2001.

27. Narumiya S., Ishizaki T. and Uehata M., Use and properties of ROCK-specific inhibitor Y-27632. Meth. Enzymol. 325: 273-284, 2000.

28. Fukuhara S., Chikumi H. and Gutkind J.S., Leukemiaassociated Rho guanine nucleotide exchange factor (LARG) links heterotrimeric $G$ proteins of the $G(12)$ family to Rho. FEBS Lett. 485: 183-188, 2000.

29. Booden M.A., Siderovski D.P. and Der C.J., Leukemiaassociated Rho guanine nucleotide exchange factor promotes $\mathrm{G}$ alpha q-coupled activation of RhoA. Mol. Cell Biol. 22: 4053-4061, 2002.

30. Fukuhara S., Murga C., Zohar M., Igishi T. and Gutkind J.S., A novel PDZ domain containing guanine nucleotide exchange factor links heterotrimeric $\mathrm{G}$ proteins to Rho. J. Biol. Chem. 274: 5868-5879, 1999.

31. Hart M.J., Jiang X., Kozasa T., Roscoe W., Singer W.D., Gilman A.G., Sternweis P.C. and Bollag G., Direct stimulation of the guanine nucleotide exchange activity of p115 RhoGEF by Galpha13. Science 280: 2112-2114, 1998.

32. Diviani D., Soderling J. and Scott J.D., AKAP-Lbc anchors protein kinase A and nucleates Galpha 12-selective Rho-mediated stress fiber formation. J. Biol. Chem. 276: 44247-44257, 2001

33. Chang Y.C., Lee H.H., Chen Y.J., Bokoch G.M. and Chang Z.F., Differential regulation of RhoA in phorbol esterinduced pro-apoptotic and differentiating cells through GEF-H1. Cell Death Differ. (revised).

34. Krendel M., Zenke F.T. and Bokoch G.M., Nucleotide exchange factor GEF-H1 mediates cross-talk between microtubules and the actin cytoskeleton. Nat. Cell Biol. 4: 294-301, 2002.

35. Ren Y., Li R., Zheng Y. and Busch H., Cloning and characterization of GEF-H1, a microtubule-associated guanine nucleotide exchange factor for Rac and Rho GTPases. J. Biol. Chem. 273: 34954-34960, 1998.

36. Benais-Pont G., Punn A., Flores-Maldonado C., Eckert J., Raposo G., Fleming T.P., Cereijido M., Balda M.S. and Matter K., Identification of a tight junction-associated guanine nucleotide exchange factor that activates Rho and regulates paracellular permeability. J. Cell Biol. 160: 729740, 2003.

37. Kosako H., Yoshida T., Matsumura F., Ishizaki T., Narumiya S. and Inagaki M., Rho-kinase/ROCK is involved in cytokinesis through the phosphorylation of myosin light chain and not ezrin/radixin/moesin proteins at the cleavage furrow. Oncogene 19: 6059-6064, 2000.

38. Gomez-Angelats M. and Cidlowski J.A., Molecular evidence for the nuclear localization of FADD. Cell Death Differ. 10: 791-797, 2003.

39. Morgan M., Thorburn J., Pandolfi P.P. and Thorburn A., Nuclear and cytoplasmic shuttling of TRADD induces apoptosis via different mechanisms. J. Cell Biol. 157: 975984, 2002.
40. Schickling O., Stegh A.H., Byrd J. and Peter M.E., Nuclear localization of DEDD leads to caspase-6 activation through its death effector domain and inhibition of RNA polymerase I dependent transcription. Cell Death Differ. 8: 1157-1168, 2001

41. Besse B., Cande C., Spano J.P., Martin A., Khayat D., Le Chevalier T., Tursz T., Sabatier L., Soria J.C. and Kroemer G., Nuclear localization of apoptosis protease activating factor-1 predicts survival after tumor resection in early-stage non-small cell lung cancer. Clin. Cancer Res. 10: 5665-5669, 2004.

42. Ruiz-Vela A., Gonzalezde Buitrago G. and Martinez A.C., Nuclear Apaf-1 and cytochrome c redistribution following stress-induced apoptosis. FEBS Lett. 517: 133$138,2002$.

43. Lai J.M., Wu S., Huang D.Y. and Chang Z.F., Cytosolic retention of phosphorylated extracellular signal-regulated kinase and a Rho-associated kinase-mediated signal impair expression of $\mathrm{p} 21(\mathrm{Cip} 1 / \mathrm{Waf} 1)$ in phorbol 12-myristate-13acetate-induced apoptotic cells. Mol. Cell Biol. 22: 75817592, 2002.

44. Lee H.H., Chien C.L., Liao H.K., Chen Y.J. and Chang Z.F., Nuclear efflux of heterogeneous nuclear ribonucleoprotein $\mathrm{C} 1 / \mathrm{C} 2$ in apoptotic cells: a novel nuclear export dependent on Rho-associated kinase activation. J. Cell Sci. 117: 5579-5589, 2004.

45. Krecic A.M. and Swanson M.S., hnRNP complexes: composition, structure, and function. Curr. Opin. Cell Biol. 11: 363-371, 1999.

46. Huang M., Rech J.E., Northington S.J., Flicker P.F., Mayeda A., Krainer A.R. and LeStourgeon W.M., The Cprotein tetramer binds 230 to 240 nucleotides of premRNA and nucleates the assembly of $40 \mathrm{~S}$ heterogeneous nuclear ribonucleoprotein particles. Mol. Cell Biol. 14: 518-533, 1994.

47. Choi Y.D., Grabowski P.J., Sharp P.A. and Dreyfuss G., Heterogeneous nuclear ribonucleoproteins: role in RNA splicing. Science 231: 1534-1539, 1986.

48. McAfee J.G., Soltaninassab S.R., Lindsay M.E. and LeStourgeon W.M., Proteins C1 and C2 of heterogeneous nuclear ribonucleoprotein complexes bind RNA in a highly cooperative fashion: support for their contiguous deposition on pre-mRNA during transcription. Biochemistry 35: 1212-1222, 1996.

49. Pinol-Roma S. and Dreyfuss G., Shuttling of pre-mRNA binding proteins between nucleus and cytoplasm. Nature 355: 730-732, 1992.

50. Nakielny S. and Dreyfuss G., Transport of proteins and RNAs in and out of the nucleus. Cell 99: 677-690, 1999.

51. Nakielny S. and Dreyfuss G., The hnRNP C proteins contain a nuclear retention sequence that can override nuclear export signals. J. Cell Biol. 134: 1365-1373, 1996.

52. Williamson D.J., Banik-Maiti S., DeGregori J. and Ruley H.E., hnRNP $\mathrm{C}$ is required for postimplantation mouse development but is dispensable for cell viability. Mol. Cell Biol. 20: 4094-4105, 2000.

53. Holcik M., Gordon B.W. and Korneluk R.G., The internal ribosome entry site-mediated translation of antiapoptotic protein XIAP is modulated by the heterogeneous nuclear ribonucleoproteins C1 and C2. Mol. Cell Biol. 23: 280-288, 2003.

54. Lewis S.M. and Holcik M., IRES in distress: translational regulation of the inhibitor of apoptosis proteins XIAP and HIAP2 during cell stress. Cell Death Differ. 12: 547-553, 2005. 
55. Kim J.H., Paek K.Y., Choi K., Kim T.D., Hahm B., Kim K.T. and Jang S.K., Heterogeneous nuclear ribonucleoprotein $\mathrm{C}$ modulates translation of $\mathrm{c}-\mathrm{myc} \mathrm{mRNA}$ in a cell cycle phase-dependent manner. Mol. Cell Biol. 23: 708-720, 2003.

56. Thornberry N.A. and Lazebnik Y., Caspases: enemies within. Science 281: 1312-1316, 1998.

57. Muzio M., Chinnaiyan A.M., Kischkel F.C., O'Rourke K., Shevchenko A., Ni J., Scaffidi C., Bretz J.D., Zhang M., Gentz R., Mann M., Krammer P.H., Peter M.E. and Dixit V.M., FLICE, a novel FADD-homologous ICE/CED-3like protease, is recruited to the CD95 (Fas/APO-1) deathinducing signaling complex. Cell 85: 817-827, 1996.

58. Strasser A., O'Connor L. and Dixit V.M., Apoptosis signaling. Annu. Rev. Biochem. 69: 217-245, 2000.

59. Yang X., Chang H.Y. and Baltimore D., Autoproteolytic activation of pro-caspases by oligomerization. Mol. Cell 1: 319-325, 1998

60. Ashkenazi A. and Dixit V.M., Death receptors: signaling and modulation. Science 281: 1305-1308, 1998.

61. Kischkel F.C., Lawrence D.A., Tinel A., LeBlanc H., Virmani A., Schow P., Gazdar A., Blenis J., Arnott D. and Ashkenazi A., Death receptor recruitment of endogenous caspase-10 and apoptosis initiation in the absence of caspase-8. J. Biol. Chem. 276: 46639-46646, 2001.

62. Vincenz C. and Dixit V.M., Fas-associated death domain protein interleukin-1beta-converting enzyme 2 (FLICE2), an ICE/Ced-3 homologue, is proximally involved in CD95and p55-mediated death signaling. J. Biol. Chem. 272: 6578-6583, 1997.

63. Wang J., Chun H.J., Wong W., Spencer D.M. and Lenardo M.J., Caspase-10 is an initiator caspase in death receptor signaling. Proc. Natl. Acad. Sci. USA 98: 13884-13888, 2001.

64. Jin Y., Atkinson S.J., Marrs J.A. and Gallagher P.J., Myosin ii light chain phosphorylation regulates membrane localization and apoptotic signaling of tumor necrosis factor receptor-1. J. Biol. Chem. 276: 30342-30349, 2001.

65. Kulms D., Dussmann H., Poppelmann B., Stander S., Schwarz A. and Schwarz T., Apoptosis induced by disruption of the actin cytoskeleton is mediated via activation of CD95 (Fas/APO-1). Cell Death Differ. 9: 598-608, 2002.

66. Takada Y., Hachiya M., Osawa Y., Hasegawa Y., Ando K., Kobayashi $\mathrm{Y}$ and Akashi M., 12-O-Tetradecanoylphorbol-13-acetate-induced apoptosis is mediated by tumor necrosis factor alpha in human monocytic U937 cells. J. Biol. Chem. 274: 28286-28292, 1999.

67. Gonzalez-Guerrico A.M. and Kazanietz M.G., Phorbol ester-induced apoptosis in prostate cancer cells via autocrine activation of the extrinsic apoptotic cascade: a key role for protein kinase C $\delta$. J. Biol. Chem. 280: 38982-38991, 2005.

68. Stupack D.G., Puente X.S., Boutsaboualoy S., Storgard C.M. and Cheresh D.A., Apoptosis of adherent cells by recruitment of caspase- 8 to unligated integrins. J. Cell Biol. 155: 459-470, 2001.

69. Carter C.A., Protein kinase $\mathrm{C}$ as a drug target: implications for drug or diet prevention and treatment of cancer. Curr. Drug Targets 1: 163-183, 2000.

70. Barandier C., Ming X.F., Rusconi S. and Yang Z., PKC is required for activation of ROCK by RhoA in human endothelial cells. Biochem. Biophys. Res. Commun. 304: 714-719, 2003.

71. Harrington E.O., Shannon C.J., Morin N., Rowlett H., Murphy C. and Lu Q., PKCdelta regulates endothelial basal barrier function through modulation of RhoA GTPase activity. Exp. Cell Res. 308: 407-421, 2005.
72. Ling M., Troller U., Zeidman R., Lundberg C. and Larsson C., Induction of neurites by the regulatory domains of PKCdelta and epsilon is counteracted by PKC catalytic activity and by the RhoA pathway. Exp. Cell Res. 292: 135-150, 2004.

73. Pang H. and Bitar K.N., Direct association of RhoA with specific domains of PKC-alpha. Am. J. Physiol. Cell Physiol. 289: C982-993, 2005.

74. Brandt D., Gimona M., Hillmann M., Haller H. and Mischak H., Protein kinase $\mathrm{C}$ induces actin reorganization via a Src- and Rho-dependent pathway. J. Biol. Chem. 277: 20903-20910, 2002.

75. Newton A.C., Regulation of protein kinase C. Curr. Opin. Cell Biol. 9: 161-167, 1997.

76. Chen C.H., Wang W.J., Kuo J.C., Tsai H.C., Lin J.R., Chang Z.F. and Chen R.H., Bidirectional signals transduced by DAPK-ERK interaction promote the apoptotic effect of DAPK. EMBO J. 24: 294-304, 2005.

77. Deiss L.P., Feinstein E., Berissi H., Cohen O. and Kimchi A., Identification of a novel serine/threonine kinase and a novel $15-\mathrm{kD}$ protein as potential mediators of the gamma interferon-induced cell death. Genes Dev. 9: 15-30, 1995

78. Cohen O., Feinstein E. and Kimchi A., DAP-kinase is a $\mathrm{Ca}^{2+} /$ calmodulin-dependent, cytoskeletal-associated protein kinase, with cell death-inducing functions that depend on its catalytic activity. EMBO J. 16: 998-1008, 1997.

79. Cohen O., Inbal B., Kissil J.L., Raveh T., Berissi H., Spivak-Kroizaman T., Feinstein E. and Kimchi A., DAPkinase participates in TNF-alpha- and Fas-induced apoptosis and its function requires the death domain. J. Cell Biol. 146: 141-148, 1999.

80. Inbal B., Cohen O., Polak-Charcon S., Kopolovic J., Vadai E., Eisenbach L. and Kimchi A., DAP kinase links the control of apoptosis to metastasis. Nature 390: 180-184, 1997.

81. Raveh T., Droguett G., Horwitz M.S., DePinho R.A. and Kimchi A., DAP kinase activates a p19ARF/p53-mediated apoptotic checkpoint to suppress oncogenic transformation. Nat. Cell Biol. 3: 1-7, 2001.

82. Jang C.W., Chen C.H., Chen C.C., Chen J.Y., Su Y.H. and Chen R.H., TGF-beta induces apoptosis through Smadmediated expression of DAP-kinase. Nat. Cell Biol. 4: 5158, 2002.

83. Pelled D., Raveh T., Riebeling C., Fridkin M., Berissi H., Futerman A.H. and Kimchi A., Death-associated protein (DAP) kinase plays a central role in ceramide-induced apoptosis in cultured hippocampal neurons. J. Biol. Chem. 277: 1957-1961, 2002.

84. Strair R.K., Schaar D., Goodell L., Aisner J., Chin K.V., Eid J., Senzon R., Cui X.X., Han Z.T., Knox B., Rabson A.B., Chang R. and Conney A., Administration of a phorbol ester to patients with hematological malignancies: preliminary results from a phase I clinical trial of 12-Otetradecanoylphorbol-13-acetate. Clin. Cancer Res. 8: 2512-2518, 2002.

85. Barry O.P. and Kazanietz M.G., Protein kinase C isozymes, novel phorbol ester receptors and cancer chemotherapy. Curr. Pharm. Des. 7: 1725-1744, 2001.

86. Madhusudan S., Protheroe A., Propper D., Han C., Corrie P., Earl H., Hancock B., Vasey P., Turner A., Balkwill F., Hoare S. and Harris A.L., A multicentre phase II trial of bryostatin-1 in patients with advanced renal cancer. Br. J. Cancer. 89: 1418-1422, 2003. 